\title{
Is it Bad to be Good? An Exploration of Aggressive and Prosocial Behavior Subtypes in Adolescence
}

\author{
Paul Boxer, ${ }^{1}$ Marie S. Tisak, ${ }^{2}$ and Sara E. Goldstein ${ }^{3}$
}

Received September 23, 2002; revised April 29, 2003; accepted May 16, 2003

Research in aggressive behavior development has distinguished between proactive (i.e., intended to achieve an instrumental goal) and reactive (i.e., emitted as an emotional response to provocation) subtypes of aggression. A similar distinction has not been made with regard to prosocial behavior. In this study, subtypes of both aggressive and prosocial behavior and their relation to aggression-supporting social cognitions were examined in a sample of 250 early and middle adolescents. Adolescents completed behavior rating scales and a measure of their beliefs about the acceptability of responding aggressively. Principal components analysis identified 3 subtypes of aggressive and prosocial behavior: aggressive, prosocial, and proactive prosocial. Proactive prosocial behavior was positively correlated with aggression and aggression-supporting beliefs, while other prosocial behavior was negatively correlated with these constructs. Findings are discussed in the context of aggressive behavior development and with regard to traditional views of prosocial behavior as altruistic.

KEY WORDS: aggression; prosocial behavior; normative/acceptability beliefs.

\section{INTRODUCTION}

In recent years, there has been an increase in social and psychological research on the various forms and functions of youth aggression, and their differential associations with social and psychological adjustment (e.g., Crick and Dodge, 1996; Smithmeyer et al., 2000). This has oc-

\footnotetext{
${ }^{1}$ Assistant Research Scientist in the Aggression Research Program of the University of Michigan's Research Center for Group Dynamics. Received PhD in Psychology from Bowling Green State University. Major research interests are the development, prevention, and treatment of child and adolescent aggressive behavior. To whom correspondence should be addressed at Research Center for Group Dynamics, 5034 ISR, University of Michigan, 426 Thompson Street, Ann Arbor, Michigan 48106; e-mail: boxerp@umich.edu.

${ }^{2}$ Professor of Psychology at Bowling Green State University. Received $\mathrm{PhD}$ in Psychological Studies in Education from Stanford University. Major research interests are the development of social behavior and social cognition, with an emphasis on aggression.

${ }^{3}$ Postdoctoral Fellow in the Gender and Achievement Research Program of the University of Michigan's Institute for Research on Women and Gender. Received PhD in Psychology from Bowling Green State University. Major research interests are social development and gender in childhood and adolescence, with a focus on peer relationships and aggression.
}

curred in tandem with greater research interest in the prevention of youth aggression (Acosta et al., 2001). A common distinction made in aggression research is between proactive (i.e., nonemotional and intended to achieve an instrumental goal) and reactive (i.e., emitted as an emotional response to provocation) forms of physical and verbal aggression (Dodge, 1991). Most research on the proactive-reactive distinction has focused on children, and thus little is known about this distinction among adolescents. Researchers also have identified a variety of prosocial subtypes, such as altruistic prosocial action (e.g., Carlo and Randall, 2002; Maynard et al., 2003), but these have not been in line with a proactive-reactive distinction. Prosocial behavior also has been under-studied among adolescents (Fabes et al., 1999; Maynard et al., 2003).

Recent research suggests that certain forms of prosocial behavior might operate from motivations similar to those underlying aggression (e.g., self-interest; Carlo \& Randall, 2002). In this study, we explored whether a proactive-reactive typology could be identified for both aggressive and prosocial behavior in a sample of adolescents, and the interrelations among those subtypes. Understanding the potentially complex relations among 
aggression and prosocial behavior can have implications for the assessment and prevention of youth aggression.

\section{Subtyping Aggressive Behavior}

Researchers have long observed distinctions between proactive and reactive forms of aggressive behavior (Dodge, 1991). Proactive aggression is nonemotional, goal-directed behavior (e.g., one child shoving another in order to get ahead in line). In contrast, reactive aggression is provoked by a negative situational reaction (e.g., one child striking another out of fear or anger). Support for this typology has been demonstrated primarily in 2 ways. First, studies using teacher or careworker reports of overtly aggressive behaviors such as hitting and threatening others have yielded consistent validity for the proactive-reactive distinction (e.g., Brown et al., 1996; Camodeca et al., 2002; Day et al., 1992; Dodge and Coie, 1987). Second, studies using direct observations of children's play groups have used observational coding procedures to identify proactive-reactive differences (e.g., Poulin and Boivin, 1999, 2000).

Little research has addressed the proactive-reactive distinction using self-report methodology, which is surprising given that the distinction hinges upon subjective motivational experiences. This may be due to the fact that most research examining differences between proactive and reactive aggression has utilized samples of children, who might not provide accurate reports of their own internal states. Studies with adolescents might yield more reliable information with regard to subjective experiences with both forms of aggression.

Researchers have shown that specific cognitive processes can discriminate between proactively and reactively aggressive youth. For example, proactive aggressors tend to hold more positive outcome expectancies for aggressive responding (i.e., expecting desirable outcomes from aggression) than reactive aggressors (Crick and Dodge, 1996; Schwartz et al., 1998; Smithmeyer et al., 2000). Further, reactive aggressors tend more often to display hostile attributional biases (i.e., attributing hostile intent to ambiguous provocation) than proactive aggressors (Crick and Dodge, 1996; Schwartz et al., 1998).

One cognitive variable that has been identified as critical to the maintenance of aggressive responding generally is the normative belief (Eron, 2001; Huesmann, 1998; Huesmann and Guerra, 1997) or the belief in the acceptability of a particular behavior (reviewed in Tisak, 1995; Turiel, 1983, 1998). These beliefs concern the perceived appropriateness of behavior (i.e., whether it is right or wrong, good or bad), and can inhibit or disinhibit aggres- sive responding. Huesmann and Guerra (1997) showed that aggression in early childhood predicted increases in the general acceptability of aggressive behavior in later childhood, as well as the acceptability of aggression as a form of retaliation. These beliefs subsequently predicted increases in actual aggression. Crane-Ross et al. (1998) found that believing aggression to be a legitimate response predicted aggressive behavior in a sample of adolescents. Erdley and Asher (1998) found that children who endorsed the legitimacy of aggression were not only more aggressive than their peers, but less prosocial.

Normative/acceptability beliefs have not been studied with regard to the proactive-reactive typology. However, as noted, normative/acceptability beliefs serve either to permit or prohibit aggressive responses. Thus, proactive aggressors should hold more approving beliefs about the use of aggression than reactive aggressors, given the deliberate versus undercontrolled nature of the 2 subtypes. Normative/acceptability beliefs might therefore be utilized productively with regard to highlighting and understanding the proactive-reactive distinction.

\section{Subtyping Prosocial Behavior}

Eron and Huesmann (1984) presented evidence to suggest that, statistically speaking, prosocial behavior is the opposite of aggressive behavior. In a longitudinal investigation, the authors found consistent negative correlations between indicators of these constructs. For example, popularity with peers (as an index of being liked) and aggression anxiety (as a disinhibitor of aggressive responding) at age 8 strongly negatively predicted criminal convictions at age 30. As described, Erdley and Asher (1998) also found that aggression and prosocial action were inversely related. Such findings suggest that children and adolescents who display prosocial behavior will generally not display aggressive behavior, and vice versa. Research on the development of prosocial action has demonstrated that such behavior emerges in concordance with empathy and perspective-taking ability (for reviews, see Eisenberg and Fabes, 1998; Hay, 1994), which overtly aggressive children and adolescents typically lack (Björkvist $e t$ al., 2000; Miller and Eisenberg, 1988). This suggests that children and adolescents who behave prosocially do so out of a concern for others (Jackson and Tisak, 2001; Tisak and Ford, 1986). A similar conception of the relation between prosocial behavior and aggression is reflected in interventions for aggressive children and adolescents (Goldstein et al., 1998), which typically seek to replace aggression (e.g., fighting) with prosocial skills (e.g., resolving conflict appropriately). 
Recent research has identified variations in the expression of prosocial behavior. For example, Tisak and her colleagues (Jackson and Tisak, 2001; Tisak and Ford, 1986) have shown that even behaviors commonly viewed as prosocial in nature (e.g., helping, sharing, comforting) are evaluated differently by children and thus may serve different interpersonal functions. Furthermore, Maynard et al. (2003) demonstrated that adolescents consider the context of the situation (e.g., accidental, academic, emotional, or social) in determining whether they would respond in a prosocial manner.

In a related but different focus of research, Carlo and Randall (2002) developed a measure of prosocial tendencies for adolescents to validate a typology of situationspecific action including public (in front of others and selfinterested), anonymous (actor remains unknown), dire (in a crisis), emotional (in response to another's emotional cues), compliant (when requested), and altruistic prosocial behaviors. Those researchers demonstrated that adolescents who reported high levels of public prosocial action showed more hedonistic and approval-oriented moral reasoning and less sympathy than their peers. In contrast, those reporting relatively high levels of emotional or compliant prosocial behavior showed higher levels of prosocial moral reasoning, more sympathy, and better perspectivetaking than peers.

Researchers have generally not attended to whether motivational subtypes of prosocial behavior might exist similar to those identified for aggressive behaviorthat is, whether there are proactive (i.e., instrumental and nonemotional) or reactive (i.e., in response to internal emotional arousal) motivations underlying interpersonal prosocial action regardless of the situational contingencies. To illustrate, a child might act prosocially towards a peer only when placed in a positive emotional state by that peer (reactive behavior). In contrast, another child might act prosocially only when some personal reward is involved (proactive behavior). A proactive-reactive distinction emphasizes global motivational aspects of behavior.

An investigation of specific subtypes might suggest a particular brand of prosocial action positively linked to aggression rather than altruism. As shown by Carlo and Randall (2002), adolescents endorsing high levels of public prosocial behavior may do so out of self-interest. It thus is possible that seemingly altruistic behaviors such as helping and complimenting others can be emitted as the function of self-interest. This behavioral style may not look like aggression on the surface. However, it might be a socially functional manifestation of a social-cognitive style in which others are devalued, self-interest is paramount, and aggression is acceptable.

\section{Gender and Age Differences in Subtypes of Aggressive and Prosocial Behavior}

Considerable previous research has demonstrated that males typically engage in more direct or overt aggression (e.g., hitting, making physical threats) than do females (e.g., Crick and Grotpeter, 1995; Lagerspetz et al., 1988; Tisak et al., 1996). However, studies of the proactive-reactive distinction have focused almost entirely on samples of school-age boys. Thus, little is known regarding gender differences among adolescents in the expression of proactive or reactive aggression. Regarding prosocial behavior, girls typically engage in more helping behavior than boys (Fabes et al., 1999; Maynard et al., 2003; Pakaslahti and Keltikangaas-Järvinen, 2001) and endorse the use of prosocial responding more than boys (Delveaux and Daniels, 2000). Additionally, Carlo and Randall (2002) reported that boys reported engaging in more public prosocial behavior than did girls, while girls reported more emotional and altruistic prosocial behavior than did boys. Thus, there appears to be evidence supporting the notion that females are more likely than males to engage in reactive forms of prosocial behavior, while males appear more likely than females to engage in proactive forms of prosocial behavior.

Age differences among adolescents in the expression of proactive and reactive behavior are more difficult to specify, given that most research on proactivereactive aggression has been conducted on child samples, and that prosocial behavior in general has been understudied among adolescents (Fabes et al., 1999; Maynard et al., 2003). However, Fabes et al. (1999) and Maynard et al. (2003) have demonstrated trends such that older adolescents report more prosocial behavior than do younger adolescents.

\section{The Current Study}

This study examined the relations among different forms of aggressive and prosocial behavior in adolescents, and the associations among those behavioral constructs and normative/acceptability beliefs about aggression. Specifically, we examined 2 types of aggression (proactive and reactive) and 3 types of prosocial behavior (proactive, reactive, and altruistic). An altruistic subtype was included because it matches a common conception of prosocial action, and we wanted to examine this form of prosocial behavior in relation to a proactive-reactive distinction.

The first goal of this study was to explore whether the prosocial and aggressive subtypes could be identified 
Boxer, Tisak, and Goldstein

through self-reports. Previous investigations of the proactive-reactive typology have utilized almost exclusively teacher (e.g., Dodge and Coie, 1987) or careworker ratings (e.g., Smithmeyer et al., 2000). A recent exception was a study by Little et al. (2000), who used self-report data from youth (grades 5 through 10) to illustrate the distinction across various forms of aggression.

The second goal of this study was to examine differences in aggressive and prosocial behavior, as well as normative/acceptability beliefs, by gender and age. Following previous research, we expected that males would report more aggression than would females. We also expected, given earlier findings, that females would report higher levels of prosocial behavior than would males. We expected that older adolescents would report more prosocial behavior than would younger adolescents, in line with Maynard et al. (2003). Given our hypothesized similarity of the 2 constructs and the findings reported by Carlo and Randall (2002), we also expected that gender and age differences in proactively prosocial behavior would resemble those of aggression. Finally, we expected males to report greater approval of aggression than females.

The final goal was to examine the associations among the specific aggressive and prosocial behavioral subtypes, and their interrelations with normative/acceptability beliefs. Previous studies have not investigated proactivereactive aggression in relation to this social-cognitive construct. Specifically, we predicted that proactive, but not reactive, aggression would correlate positively with beliefs approving of aggression. We also predicted that proactive prosocial behavior would correlate positively with aggression, as well as normative/acceptability beliefs, and altruistic and reactive prosocial behavior would relate negatively to these constructs.

\section{METHOD}

\section{Participants}

Data were obtained from students at 2 middle schools (one rural, one suburban) and one high school (suburban) in northwest Ohio. Participants were 250 adolescents $(M=14.60$ years, $\mathrm{SD}=2.00)$. There were 129 early adolescents $(7$ th and 8 th graders; $M=12.77$ years, $\mathrm{SD}=$ $0.71)$ and 121 middle adolescents (11th and 12th graders; $M=16.55$ years, $\mathrm{SD}=0.59)$. The majority of participants was female (66\%) and Caucasian (93\%). Most reported living in 2-parent homes (89\%). Sixty-four percent of participants reported that their fathers (or father figures) had obtained college educations or higher; $66 \%$ reported this for their mothers (or mother figures).

\section{Measures}

\section{Aggressive and Prosocial Behavior Questionnaire}

This questionnaire was designed to assess levels of different subtypes of prosocial (e.g., helping) and aggressive (e.g., hitting) behaviors by participants. The questionnaire contained 5 groups of 5 items each, plus 3 filler items, in randomized order. For each item, participants were asked to select the response choice that "best describes what you are like as a person." A 6-point response scale (ranging from 1 (definitely not like me) to 6 (definitely like me) was utilized.

The aggressive behavior items involved 2 subtypes consisting of 5 behaviors each (hitting, yelling at, saying mean things to, insulting, pushing, or shoving):

(a) Proactive, which involves an instrumental, goaldirected response. For example, "I often hit people to get what I want."

(b) Reactive, which involves a negative affective response to an individual. For example, "When someone makes me angry or upset, I will often hit them for it."

The prosocial items involved 3 subtypes composed of 5 behaviors each (helping, doing a favor, sharing, lending something, giving a compliment):

(a) Altruistic, which involves acting voluntarily without expectation of personal gain. For example, "I often help people without being asked."

(b) Proactive, which involves an instrumental, goaldirected response. For example, "I often help people to get what I want."

(c) Reactive, which involves a positive affective response to an individual. For example, "When someone puts me in a good mood, I will often help them if they ask."

The item groupings used on the behavior questionnaire were derived from prior research related to proactive-reactive aggression. Proactive items ("I often ... to get what I want") were based on items developed by Little et al. (2000) for measuring goal-directed, "instrumental" (i.e., proactive) aggression. The Reactive items were written in an attempt to isolate the use of aggression or prosocial behavior in response to a mood state created by another person. Altruistic items were written to highlight the voluntary nature of such behavior.

Although researchers (e.g., Dodge and Coie, 1987) have obtained factorial validity for a proactive-reactive distinction using teacher ratings, this typology has been infrequently investigated through self-reports with regard to 
aggression. Further, prosocial behavior has not previously been studied with regard to proactive and reactive subtypes. Therefore, in order to determine composite scores for the various behavioral constructs, data from the behavioral questionnaire were subjected to principal components analyses (PCA) with promax rotation. This procedure examines underlying covariance structures among items while maintaining potential correlations between identified factors. This approach was chosen because of the preliminary nature of the study.

Table I displays the results of the principal components analysis. Initial PCA of the behavioral questionnaire suggested a 5 -factor solution as indicated by eigenvalues (factors with values $>1$ ) and the scree plot. As shown, the

Table I. Coefficient Alphas and Item Factor Loadings of Behavioral Composites

\begin{tabular}{|c|c|c|c|c|c|}
\hline Factor & 1 & 2 & 3 & 4 & 5 \\
\hline \multicolumn{6}{|l|}{ Altruistic prosocial $^{a}(\alpha=.83)$} \\
\hline Do favors for people & - & - & - & 0.76 & - \\
\hline Lend things to people & - & - & - & 0.79 & - \\
\hline Help people & - & - & - & 0.86 & - \\
\hline Compliment people & - & 0.62 & - & 0.66 & - \\
\hline Share things with people & - & 0.59 & - & 0.73 & - \\
\hline \multicolumn{6}{|l|}{ 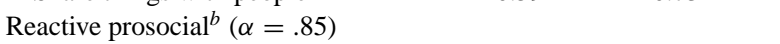 } \\
\hline Share something with them & - & 0.78 & - & - & - \\
\hline Help them & - & 0.78 & - & 0.50 & - \\
\hline Lend them something & - & 0.72 & - & 0.53 & - \\
\hline Compliment them & - & 0.74 & - & - & - \\
\hline Do them a favor & - & 0.82 & - & 0.41 & - \\
\hline \multicolumn{6}{|l|}{ Proactive prosocial $^{c}(\alpha=.90)$} \\
\hline Help people & 0.79 & - & - & - & - \\
\hline Share things with people & 0.89 & - & - & - & - \\
\hline Lend things to people & 0.84 & - & - & - & - \\
\hline Do favors for people & 0.86 & - & - & - & - \\
\hline Compliment people & 0.86 & - & - & - & - \\
\hline \multicolumn{6}{|l|}{ Reactive aggressive $^{d}(\alpha=.85)$} \\
\hline Push or shove them & - & - & 0.63 & - & 0.59 \\
\hline Yell at them & - & - & - & - & 0.84 \\
\hline Insult them & - & - & - & - & 0.85 \\
\hline Hit them & - & - & 0.63 & - & 0.64 \\
\hline Say mean things to them & - & - & 0.51 & - & 0.87 \\
\hline \multicolumn{6}{|l|}{ Proactive aggressive $^{e}(\alpha=.79)$} \\
\hline Insult people & - & - & 0.63 & - & 0.59 \\
\hline Hit people & - & - & 0.58 & - & - \\
\hline Push or shove people & - & - & 0.81 & - & - \\
\hline Say mean things to people & - & - & 0.83 & - & 0.46 \\
\hline Yell at people & - & - & 0.74 & - & - \\
\hline Eigenvalues & 6.86 & 4.74 & 2.02 & 1.57 & 1.15 \\
\hline
\end{tabular}

"Items read as, "I often ... without being asked."

${ }^{b}$ Items read as, "When someone puts me in a good mood, I will often ... if they ask."

${ }^{c}$ Items read as, "I often ... to get what I want."

${ }^{d}$ Items read as, "When someone makes me angry or upset, I will often ... for it."

${ }^{e}$ Items read as, "I often ... to get what I want."
Table II. Intercorrelations Among Initial Behavioral Composites

\begin{tabular}{lccccc}
\hline \multicolumn{1}{c}{ Composite } & 1 & 2 & 3 & 4 & 5 \\
\hline 1. Altruistic prosocial & - & & & & \\
2. Reactive prosocial & $.61^{*}$ & - & & & \\
3. Proactive prosocial & -.05 & $.19^{*}$ & - & & \\
4. Reactive aggressive & $-.28^{*}$ & -.07 & $.35^{*}$ & - & \\
5. Proactive aggressive & $-.29^{*}$ & $-.19^{*}$ & $.34^{*}$ & $.62^{*}$ & - \\
${ }^{*} p<.01$. & & & & & \\
\end{tabular}

5 factors extracted aligned somewhat with the aggressive and prosocial subtypes. However, Proactive Prosocial behavior was the only factor with zero item cross-loadings. Table II displays the bivariate correlations among the initial 5 subscales. Given the high correlations and factorial cross-loadings between the Altruistic/Reactive prosocial and Proactive/Reactive aggression subscales, composites were created using these subscale pairs. Thus, a 10-item Combined Prosocial $(\alpha=.88)$ composite was created by computing means based on all of the Altruistic and Reactive prosocial behavior items. A 10-item Aggressive Behavior $(\alpha=.87)$ composite was created by computing means based on all of the Proactive and Reactive aggressive behavior items. The 5-item Proactive Prosocial $(\alpha=.90)$ also was retained for inferential analyses.

Table III displays the means and standard deviations of the 3 behavior constructs employed for inferential analyses, by gender and age group. Intercorrelations across the full sample among these new behavioral composites were similar to the pattern suggested in Table II. Aggressive and Proactive Prosocial behavior were significantly positively correlated $(r=.37, p<.01)$, while Aggressive and Combined Prosocial behavior were significantly negatively correlated $(r=-.24, p<.01)$. Combined Prosocial and Proactive Prosocial behavior were uncorrelated $(r=.07, \mathrm{~ns})$.

\section{Normative Beliefs About Aggression Scale (NOBAGS; Huesmann and Guerra, 1997)}

The NOBAGS is a 20 -item scale designed to measure beliefs about the acceptability of aggressive behavior. The measure contains 2 subscales: Retaliation Approval (12 items assessing beliefs about the acceptability of retaliating in aggressive ways to aggressive provocation) and General Approval ( 8 items assessing beliefs about the acceptability of aggression in general).

Items on the Retaliation Approval subscale $(\alpha=.86)$ consist of brief ( 1 sentence) vignette descriptions of aggressive behavior. For example, "Suppose a boy hits another boy, John." Participants then rate the acceptability of 
Table III. Means and Standard Deviations for Behavior Composites by Gender and Age Group

\begin{tabular}{|c|c|c|c|c|c|c|c|c|}
\hline \multirow[b]{3}{*}{ Composite } & \multicolumn{4}{|c|}{ Boys $(n=84)$} & \multicolumn{4}{|c|}{ Girls $(n=166)$} \\
\hline & \multicolumn{2}{|c|}{ Early adolescent $(n=48)$} & \multicolumn{2}{|c|}{ Middle adolescent $(n=36)$} & \multicolumn{2}{|c|}{ Early adolescent $(n=81)$} & \multicolumn{2}{|c|}{ Middle adolescent $(n=85)$} \\
\hline & $M$ & $\mathrm{SD}$ & $M$ & $\mathrm{SD}$ & $M$ & SD & $M$ & SD \\
\hline Combined prosocial & 4.41 & .97 & 4.53 & 1.00 & 4.76 & .98 & 4.92 & .76 \\
\hline Proactive prosocial & 3.05 & 1.36 & 3.41 & 1.44 & 2.59 & 1.21 & 2.57 & 1.10 \\
\hline Aggressive & 2.13 & .88 & 2.40 & .87 & 1.92 & 1.22 & 1.63 & .54 \\
\hline
\end{tabular}

Note. M: mean; SD: standard deviation. Items scaled from 1 (Definitely not like me) to 6 (Definitely like me).

verbally and physically aggressive retaliation (e.g., "Do you think it's wrong for John to hit him back?") on a 4-point scale (ranging from 1 it's really wrong to 4 it's perfectly okay). Subscale scores were computed by taking the mean of all responses; higher scores indicate greater approval of aggressive retaliation.

Items on the General Approval subscale $(\alpha=.84)$ are written as single-sentence, general statements about aggressive acts. For example, "In general, it is wrong to hit other people." Participants are then asked to rate how "okay" or "wrong" the actions described in each statement are, using the same response format described for Retaliation Approval items. Subscale scores were computed by taking the mean of all responses; higher scores indicate greater approval of aggression in general.

\section{Procedures}

Active school and parental consent were obtained prior to any involvement in the study. Participants also provided assent for their involvement. For all participants, questionnaires were administered in a group format in classrooms or common areas. Questionnaires were presented in the order listed above, and staff were available to answer any questions. Survey administration typically lasted no more than $30 \mathrm{~min}$.

\section{RESULTS}

\section{Gender and Age Differences in Aggressive and Prosocial Behavior}

The first set of analyses examined gender and age differences in self-reported behavior. Because of the intercorrelations among the behavior composites, a multivariate analysis-of-variance (MANOVA) procedure was used to explore differences as the function of gender and age group. A2 (gender) by 2 (age group) factorial design was used, with the 3 behavior constructs as dependent variables. To protect against Type I error, alpha level for these analyses was set at .01.
A significant multivariate effect was observed for gender (Wilks's $\Lambda=.88$ ). Specifically, females reported more Combined Prosocial behavior $(M=4.84, \mathrm{SD}=$ $.87)$ than did males $(M=4.46, \mathrm{SD}=.97), F(1,246)=$ 9.03, $p<.01$. Males reported higher levels of both Aggression $(M=2.24, \mathrm{SD}=.88)$ and Proactive Prosocial behavior $(M=3.21, \mathrm{SD}=1.40)$ than did females $(\mathrm{Ag}$ gression $M=1.77, \mathrm{SD}=.75$; Proactive Prosocial $M=$ $2.58, \mathrm{SD}=1.15)$. Gender differences for Aggression were significant at $F(1,246)=21.15, p<.01$; for Proactive Prosocial, $F(1,246)=15.38, p<.01$. No significant effects emerged for age group, and no significant age group by gender interactions were evident.

\section{Gender and Age Differences in Normative Beliefs}

Table IV displays the means and standard deviations of the Normative Beliefs About Aggression Scale (NOBAGS) by gender and age group. The 2 subscales, Retaliation beliefs and General beliefs, were significantly correlated $(r=.50, p<.01)$. A 2 (gender) by 2 (age group) MANOVA was used to examine the effects of gender and age on beliefs. Alpha level for these analyses was set at .01. This analysis revealed significant multivariate main effects for both gender (Wilks' $\Lambda=.91$ ) and age (Wilks' $\Lambda=.90$ ). Males (Retaliation $M=1.98$, $\mathrm{SD}=.56$; General $M=1.53, \mathrm{SD}=.51)$ were more approving than females (Retaliation $M=1.75, \mathrm{SD}=.46$; General $M=1.32, \mathrm{SD}=.36$ ) of both types of beliefs. Gender differences for Retaliation beliefs were significant at $F(1,246)=3.89, p<.01$; for General beliefs, $F(1,246)=3.00, p<.01$. Middle adolescents $(M=$ $1.97, \mathrm{SD}=.50)$ were more approving than early adolescents $(M=1.69, \mathrm{SD}=.48)$ of Retaliation beliefs, $F(1,246)=6.34, p<.01$. There were no significant interaction effects.

\section{Associations Between Behaviors and Beliefs}

The final set of analyses explored the relation between self-reported behaviors and beliefs related to 
Table IV. Means and Standard Deviations for NOBAGS Subscales by Gender and Age Group

\begin{tabular}{|c|c|c|c|c|c|c|c|c|}
\hline \multirow[b]{3}{*}{ Subscale } & \multicolumn{4}{|c|}{ Boys $(n=84)$} & \multicolumn{4}{|c|}{ Girls $(n=166)$} \\
\hline & \multicolumn{2}{|c|}{ Early adolescent $(n=48)$} & \multicolumn{2}{|c|}{ Middle adolescent $(n=36)$} & \multicolumn{2}{|c|}{ Early adolescent $(n=81)$} & \multicolumn{2}{|c|}{ Middle adolescent $(n=85)$} \\
\hline & $M$ & SD & $M$ & SD & $M$ & SD & $M$ & SD \\
\hline Retaliation beliefs & 1.78 & .49 & 2.24 & .53 & 1.63 & .46 & 1.85 & .44 \\
\hline General beliefs & 1.43 & .46 & 1.67 & .55 & 1.32 & .39 & 1.31 & .33 \\
\hline
\end{tabular}

Note. $M$ : mean; SD: standard deviation. Higher values indicate greater approval of aggression.

aggression. Correlations were calculated to examine these associations, correlating each belief subscale with each behavior composite. Normative beliefs supporting the use of aggression in general were positively associated with both Aggressive $(r=.41, p<.01)$ and Proactive Prosocial $(r=.14, p<.05)$ behavior, and negatively associated with Combined Prosocial behavior $(r=-.36, p<.01)$. Normative beliefs supporting the use of aggression as retaliation were positively associated with Aggressive $(r=$ $.42, p<.01)$ and Proactive Prosocial $(r=.21, p<.01)$ behavior, and uncorrelated with Combined Prosocial behavior $(r=-.08, \mathrm{~ns})$.

\section{DISCUSSION}

Theory and empirical research on the social-cognitive correlates of aggressive behavior development hold that beliefs about the acceptability of aggression are critical to the maintenance of aggressive responding over time (Huesmann, 1998; Huesmann and Guerra, 1997). Children and adolescents who believe that aggression is an acceptable ("okay" or "right") reaction to provocation, and/or acceptable in general, are more likely than those with dissimilar beliefs to behave aggressively. The results of the present study support and extend this idea. Normative beliefs about aggression were significantly positively associated with self-reported aggressive behavior in adolescents. These beliefs were also significantly negatively associated with 1 type of prosocial behavior (i.e., a combination of altruistic and reactive forms of prosocial action). This finding implies that when adolescents believe it is unacceptable to respond aggressively, they are more likely to report behaving in certain prosocial ways.

One form of prosocial behavior representing an instrumental behavioral style (i.e., behaving prosocially to "get what I want") emerged as distinct from more altruistic and reactive forms of prosocial behavior. Validity for this proactive subtype of prosocial action was provided by principal components analysis, gender differences in reported engagement, and differential correlations with aggressive behavior and aggression-supporting beliefs. For example, self-reported proactive prosocial behavior was significantly positively correlated with aggressive, behavior, whereas other prosocial behavior was significantly negatively correlated with aggression. This study thus presents some preliminary evidence that a specific variety of prosocial behavior might operate from motivations similar to those driving aggressive behavior.

\section{Gender Differences in Behavior and Beliefs}

Consistent with expectations and much of the research on direct, overt aggressive behavior (hitting, yelling, threatening), males in this study reported engaging in higher levels of aggression than did females. Also consistent with expectations and prior research, females in this study reported engaging in higher levels of altruistic and reactive prosocial behavior. Our hypothesis concerning proactive prosocial behavior also was confirmed in that gender differences on this construct resembled those obtained for aggression - males reported engaging in higher levels of this behavior than did females. We also observed that males endorsed greater approval of aggressive retaliation, and aggression in general, than did females.

\section{Age Differences in Behavior and Beliefs}

Differences by age in aggressive and prosocial behavior, and normative/acceptability beliefs regarding aggression, were less consistent across constructs than were gender differences. Middle adolescents did not report greater engagement in either aggressive or prosocial behavior than did early adolescents. With regard to aggressive behavior, this might be related to a stabilization of levels of aggression in adolescence. Although researchers have noted changes in mean levels of aggressive behavior from infancy to childhood and into early adolescence (e.g., Tremblay, 2000), variation through adolescence might be less striking and thus more difficult to detect. Still, we did observe that middle adolescents endorsed significantly greater approval of aggressive retaliation than did early 
adolescents. This suggests that with age, and therefore lengthier exposure to and experience with aggression, adolescents become more accepting of aggression as a behavioral response to provocation.

\section{Associations Between Behaviors and Beliefs}

Aggressive and prosocial behavior were related to normative/acceptability beliefs in the expected ways. Of particular interest, however, were the correlations observed for proactive prosocial behavior. In addition to being positively correlated with aggression, and uncorrelated with other prosocial behavior (i.e., reactive, altruistic), engagement in proactive prosocial behavior was positively correlated with beliefs approving of aggression. This finding suggests that proactive prosocial behavior might originate from motivations and beliefs more similar to aggression than to prosocial behavior in general.

\section{The Proactive Subtype of Prosocial Behavior}

Proactive prosocial behavior, as measured in the current investigation, represents a manipulative, selfinterested, and goal-directed form of prosocial behavior. This is in contrast to traditional conceptions of prosocial behavior as largely altruistic in origin and voluntary (e.g., Hay, 1994), and seems even more selfishly motivated than Carlo and Randall's public prosocial behavior (Carlo and Randall, 2002). The results of the current study suggest that prosocial actions can stem from motivations other than simply "being nice," or even being nice in order to impress others. Proactively prosocial behavior, although apparently similar in form to typical prosocial action, serves a different purpose. Prosocial behavior more closely aligned with aggression than altruism creates an interesting puzzle for researchers and practitioners: Can it be "bad" to be "good"?

Proactive prosocial behavior seems similar to indirect/relational forms of aggression such as gossip and peer exclusion (Björkqvist, 1994; Crick, 1995; Lagerspetz and Björkqvist, 1994). Both types of behavior reflect more socially sophisticated and manipulative means of pursuing self-interested goals than do direct/overt forms of aggressive behavior such as hitting and pushing. Neither socially manipulative aggression nor a proactive motivation for prosocial behavior would be easy for an outside observer to detect. Therefore, both types of behavior reflect ways that a youth might manipulate peers to get what she or he wants, while minimizing or eliminating any chance for punishment. Still, while relational aggression harms others, proactive prosocial behavior ostensibly results in favorable outcomes for recipients. Proactive prosocial behavior could therefore be considered a socially acceptable, adaptive means of achieving control over others for goal attainment.

Even so, the results of this study imply that proactive prosocial behavior should be understood as a construct that could have potential negative implications with regard to the youth who engage in it. In this study, proactive prosocial behavior was correlated at $.38(p<.01)$ with aggression. This suggests that some adolescents who report engaging in seemingly "nice" behavior (e.g., helping others) are also likely to report performing decidedly not-nice behaviors such as hitting and insulting others. It seems obvious that prosocial behavior would not necessarily injure or irritate others, and therefore not fit a classic definition of aggression advanced by Eron and his colleagues (Eron, 1987; Eron et al., 1971). However, emitted in the context of an aggressive/proactive prosocial actor assuming interpersonal control, such behavior could, over time, lead to a dyadic relationship more similar to that of bully-victim (Olweus, 1997) than of a friendly tie. In such a dyad, one actor utilizes an imbalance of power to control another. Thus, it might be useful for researchers and practitioners to integrate an awareness of proactive prosocial behavior into studies of bully-victim relations, as well as the development of programs targeting bullying among youth, such as teacher training (e.g., O'Moore, 2000).

\section{Limitations and Future Directions}

This study represents an initial investigation into the subtypes of prosocial behavior, and their relations to overtly aggressive behavior. More research on this distinction in prosocial behavior, with more diverse samples (by gender, age, ethnicity) of youth, is necessary. Interestingly, our results did not support the distinction of proactive and reactive aggression identified in prior research. This might be because we utilized self-reports of behavior, while most prior research has utilized observer ratings of proactive and reactive aggression. Adolescents might not make such distinctions when conceptualizing their own aggressive behavior. Further, the fairly low levels of aggressive behavior reported across participants in this study might have attenuated any typological distinctions. Future studies might examine the relation between proactive prosocial behavior and aggression in samples of youth who engage in aggressive behavior more frequently. Future studies could also incorporate measures of indirect/relational aggression to examine whether this type of aggressive behavior is also positively associated with proactive prosocial responding. 
The findings from this study suggest that practitioners (e.g., teachers, counselors) who work with adolescents should attend carefully to their clients' beliefs about the acceptability of aggressive responding. An adolescent who appears to be "good" and prosocial in his or her orientation to others may in fact hold beliefs that disregard the welfare of others. Viewed this way, proactive prosocial behavior more closely resembles a low-impact form of antisocial behavior. Future basic research on social development and applied research on interventions for aggression should attend to the distinction in prosocial behavior observed in the present analysis.

\section{ACKNOWLEDGMENTS}

We are grateful to the principals and teachers of the middle and high schools where data collection occurred, for their time and assistance. We acknowledge the insightful feedback provided by Eric F. Dubow, Dara MusherEizenman, and Julie Burke, and anonymous reviewers on earlier versions of this work. We also extend our appreciation to Shannon Brinker and Jennifer VanScoyoc, who assisted with data collection.

\section{REFERENCES}

Acosta, O. M., Albus, K. E., Reynolds, M. W., Spriggs, D., and Weist, M. D. (2001). Assessing the status of research on violence related problems among youth. J. Clin. Child Psychol. 30: 152-160.

Björkqvist, K. (1994). Sex differences in physical, verbal, and indirect aggression: A review of recent research. Sex Roles 30: 177-188.

Björkvist, K., Österman, K., and Kaukiainen, A. (2000). Social intelligence - empathy $=$ aggression? Aggression Violent Behav. 5: 191-200.

Brown, K., Atkins, M. S., Osborne, M. L., and Milnamow, M. (1996). A revised teacher rating scale for reactive and proactive aggression. J. Abnorm. Child Psychol. 24: 473-479.

Camodeca, M., Goosens, F. A., Terwogt, M. M., and Schuengel, C. (2002). Bullying and victimization among school-age children: Stability and links to proactive and reactive aggression. Soc. Dev. 11: 332-345.

Carlo, G., and Randall, B. A. (2002). The development of a measure of prosocial behaviors for late adolescents. J. Youth Adolesc. 31: 31-44.

Crane-Ross, D., Tisak, M. S., and Tisak, J. (1998). Aggression and conventional rule violation among adolescents: Social-reasoning predictors of social behavior. Aggressive Behav. 24: 347-365.

Crick, N. R. (1995). Relational aggression: The role of intent attributions, feelings of distress, and provocation type. Dev. Psychopathol. 7: 313-322.

Crick, N. R., and Dodge, K. A. (1996). Social information-processing mechanisms in reactive and proactive aggression. Child Dev. 67: 993-1002.

Crick, N. R., and Grotpeter, J. K. (1995). Relational aggression, gender, and social-psychological adjustment. Child Dev. 66: 710-722.

Day, D. M., Bream, L. A., and Pal, A. (1992). Proactive and reactive aggression: An analysis of subtypes based on teacher perceptions. J. Clin. Child Psychol. 21: 210-217.
Delveaux, K. D., and Daniels, T. (2000). Children's social cognitions: Physically and relationally aggressive strategies and children's goals in peer conflict situations. Merrill-Palmer Q. 46: 672692.

Dodge, K. A. (1991). The structure and function of reactive and proactive aggression. In Pepler, D., and Rubin, K., (eds.), The Development and Treatment of Childhood Aggression. Erlbaum, Hillsdale, NJ, pp. 201-218.

Dodge, K. A., and Coie, J. D. (1987). Social information-processing factors in reactive and proactive aggression in children's peer groups. J. Pers. Soc. Psychol. 53: 1143-1158.

Eisenberg, N., and Fabes, R. A. (1998). Prosocial development. In Damon, W., (Series ed.), and Eisenberg, N. (Vol. ed.), Handbook of Child psychology, Vol. 3: Social, emotional, and personality development. (5th ed.). Wiley, New York, pp. 701-778.

Erdley, C. A., and Asher, S. R. (1998). Linkages between children's beliefs about the legitimacy of aggression and their behavior. Soc. Dev. 7: 321-339.

Eron, L. D. (1987). The development of aggressive behavior from the perspective of a developing behaviorism. Am. Psychol. 42: 435442.

Eron, L. D. (2001). Seeing is believing: How viewing violence alters attitudes and behavior. In Bohart, A. C., and Stipek, D. J., (eds.), Constructive and Destructive Behavior: Implications for Family, School, and Society. American Psychological Association, Washington, DC, pp. 49-60.

Eron, L. D., and Huesmann, L. R. (1984). The relation of prosocial behavior to the development of aggression and psychopathology. Aggressive Behav. 10: 201-211.

Eron, L. D., Walder, L. O., and Lefkowitz, M. M. (1971). Learning of Aggression in Children. Little, Brown, Boston, MA.

Fabes, R. A., Carlo, G., Kupanoff, K., and Laible, D. (1999). Early adolescence and prosocial/moral behavior 1: The role of individual processes. J. Early Adolesc. 19: 5-16.

Goldstein, A. P., Glick, B., and Gibbs, J. C. (1998). Aggression Replacement Training: A Comprehensive Intervention for Aggressive Youth (Revised). Research Press, Champaign, IL.

Hay, D. F. (1994). Prosocial development. J. Child Psychol. Psychiatry Allied Discip. 35: 29-71.

Huesmann, L. R. (1998). The role of social information processing and cognitive schema in the acquisition and maintenance of habitual aggressive behavior. In Geen, R. G., and Donnerstein, E., (eds.), Human Aggression: Theories, Research, and Implications for Social Policy. Academic Press, San Diego, CA, pp. 73-109.

Huesmann, L. R, and Guerra, N. G. (1997). Children's normative beliefs about aggression and aggressive behavior. J. Pers. Soc. Psychol. 72: 408-419.

Jackson, M., and Tisak, M. S. (2001). Is prosocial behavior a good thing? Developmental changes in children's evaluations of helping, sharing, cooperating, and comforting. Br. J. Dev. Psychol. 19: 349-367.

Lagerspetz, K. M., and Björkqvist, K. (1994). Indirect aggression in boys and girls. In Huesmann, L. R. (ed.), Aggressive Behavior: Current Perspectives. Plenum, New York, pp. 131-150.

Lagerspetz, K. M., Björkqvist, K., and Peltonen, T. (1988). Is indirect aggression typical of females? Gender differences in aggressiveness in 11- to 12-year old children. Aggressive Behav. 14: 403-414.

Little, T. D., Jones, S. M., Henrich, C. C., and Hawley, P. H. (April, 2000). Toward a unified model of aggression: Integrating form and function. Paper presented at the Eighth Biannual Meeting of the Society for Research in Adolescence, Chicago, IL.

Maynard, A. M., Tisak, M. S., and Tisak, J. (2003). Adolescents' Intention to Respond: A Contextual Approach to the Measurement of Prosocial Judgments Involving Peers. Manuscript submitted for publication.

Miller, P. A., and Eisenberg, N. (1988). The relation of empathy to aggressive and externalizing/antisocial behavior. Psychol. Bull. 103: 324-344.

Olweus, D. (1997). Tackling peer victimization with a school-based prevention program. In Fry, D. P., and Björkqvist, K. (eds.), Cultural 
Variation in Conflict Resolution: Alternatives to Violence. Erlbaum, Mahwah, NJ, pp. 215-231.

O'Moore, M. (2000). Critical issues for teacher training to counter bullying and victimisation in Ireland. Aggressive Behav. 26: 99-111.

Pakaslahti, L., and Keltikangas-Järvinen, L. (2001). Peer-attributed prosocial behavior among aggressive/preferred, aggressive/nonpreferred, non-aggressive/preferred, and non-aggressive/nonpreferred adolescents. Pers. Individ. Differ. 30: 903-916.

Poulin, F., and Boivin, M. (1999). Proactive and reactive aggression and boys' friendship quality in mainstream classrooms.

Poulin, F., and Boivin, M. (2000). The role of proactive and reactive aggression in the formation and development of boys' friendships. Dev. Psychol. 36: 233-240.

Schwartz, D., Dodge, K. A., Coie, J. D., Hubbard, J. A., Cillessen, A. N., Lemerise, E. A., and Bateman, H. (1998). Social-cognitive and behavioral correlates of aggression and victimization in boys' play groups. J. Abnormal Child Psychol. 26: 431-440.

Smithmyer, C. M., Hubbard, J. A., and Simons, R. F. (2000). Proactive and reactive aggression in delinquent adolescents: Relations to aggression outcome expectancies. J. Clin. Child Psychol. 29: 8693.

Tisak, M. S. (1995). Domains of social reasoning and beyond. Ann. Child Dev. 11: 95-130.

Tisak, M. S., and Ford, M. E. (1986). Children's conceptions of interpersonal events. Merrill-Palmer Q. 32: 291-306.

Tisak, M. S., Nucci, L. P., and Jankowski, A. M. (1996). Preschool children's social interactions involving moral and prudential transgressions: An observational study. Early Educ. Dev. 7: 137148

Tremblay, R. E. (2000). The development of aggressive behaviour during childhood: What have we learned in the past century? Intern. J. Behav. Develop. 24: 129-141.

Turiel, E. (1983). The Development of Social Knowledge: Morality and Convention. Cambridge University Press, Cambridge, England.

Turiel, E. (1998). The development of morality. In Damon, W., (Series ed.), and Eisenberg, N. (Vol. ed.), Handbook of Child Psychology, Vol. 3: Social, Emotional, and Personality Development (5th edn.), Wiley, New York, pp. 863-932. 